\title{
Major Indian ICT Firms and Their Approaches towards Achieving Quality*
}

\author{
Dilip Dutta \& Anna Sekhar \\ School of Economics \& Political Science \\ University of Sydney \\ NSW: 2006, Australia \\ Emails: dilipd@econ.usyd.edu.au \\ asek3379@mail.usyd.edu.au
}

\begin{abstract}
Of the three basic theories of innovation: the entrepreneur theory, the technology-economics theory and the strategic theory, the third one seems to be highly appropriate for the analysis of recent growth of the information and communication technology (ICT) industry in many developing countries including India. The central measure for achieving quality by the various major Indian (ICT) firms is widely agreed to have been the adoption of Six Sigma Methodology and/or its multivariate branches like Total Quality Management (TQM), Supply Chain Management (SCM), and Customer Relationship Management (CRM). It is apparent that the main objective of the firms chosen has been to increase the pace of innovation activities, irrespective of their different area of product specialisation. Its success is believed to depend largely on the overall improvement in infrastructure, besides active market interaction. To enable both the above, a brief highlight has been made on the establishment of interaction and learning sites (ILSs) in every regional State in India. The paper concludes with a mention of the elements observed to be missing among the firms under consideration, and, thereby, delineating the scope for their further improvement.
\end{abstract}

\footnotetext{
* Paper presented at an International Conference to Mark 20 Years of ASARC, University House, Australian National University, 27 \& 28 April 2004.
} 


\title{
Major Indian ICT Firms and Their Approaches towards Achieving Quality
}

\author{
Dilip Dutta \& Anna Sekhar*
}

\section{Introduction}

Since the 1980s, there has been a resurgence of interest in the approach to assign a critical linkage role to innovation in the relationship between competition and competitiveness (Mytelka, 1999, p.15). The term innovation that engulfs R\&D includes a broad spectrum of activities like the introduction of a new product or a new product quality, introduction of a new production method or process, a new organisational or management structure, opening up of new markets, etc. In the recent analysis of innovation literature, three different explanations or basic theories have been identified: the basic entrepreneur theory (in the context of markets in process of formation), the basic technology-economics theory (suitable for established but unexploited markets) and the basic strategic theory (appropriate for complex, rapidly changing and nearly saturated markets) (Sundbo, 1998, p. 191). It should, however, be noted that there is overlapping of elements among the three basic theories.

As to various implications ${ }^{1}$ of the above three theories at the micro level, the entrepreneur theory and the strategic theory deal with all types of innovation, while technology-economics theory operates mainly with process and product innovations. From the 'management' point of view, the entrepreneur theory deals with a very low degree of management, while the other two theories operate with the management of the innovation process. Because the strategic theory involves the whole organisation in innovation development, it, therefore, operates with the most extensive and interventional management style. In the analysis of growth and development of the contemporary information and communication technology (ICT) sector ${ }^{2}$, we believe that the strategic theory gains an upper hand, particularly in the context of its recent rise in many developing countries including India.

Studies such as Mytelka (1999), Kumar (2001), etc. indicate the advantageous position of developed countries to compete better in innovation activities. Comparatively, firms in developing countries, irrespective of their size, are still in the process of learning various innovation activities from the developed nations. In India, the infancy stage of infrastructure growth has resulted in low levels of innovation activities. This said whatever little innovation has been carried out is mostly by the major Indian ICT firms.

In this paper, we would like to focus on the overall issues such as (i) the extent of innovation activities taking place in the major Indian ICT firms; (ii) scope for further improvement of

\footnotetext{
* For their immense help in obtaining valuable information and suggestion, our sincere thanks goes to Mr. Balakrishnan (Infosys); Andy Wright, Nirav Desai and Lakshminarayan Lan (WIPRO); and Rajesh Jain (Tech Samachar). Our thanks also goes to the customer support team of Reliance Industries for having taken pains to send us all the information without any bit of hesitation.

${ }^{1}$ Sundbo (1998, pp. 193-94).

${ }^{2}$ Generally speaking, information and communication technology (ICT) includes microelectronics, optoelectronics and related technologies used in collecting, storing, processing and transmission of information in the form of voice, data or image (ESCAP, 1999, p. 139).
} 
these ICT firms in particular and the ICT industry in general. For firms involved in innovation process, quality is the prime focus. Improvement in quality of products and services from the individual firm's perspective implies better sustenance and control in the market. The Indian ICT industry has witnessed a period of sustained growth during the past decade or so. Being highly competitive, most of the major Indian ICT companies have a record of achieving the highest level 5 of Software Engineering Institute-Capability Maturity Model (SEI-CMM).

Major Indian ICT firms have adopted varied approaches towards improving quality of their products and services. The central measure for achieving quality by the various major Indian ICT firms has been the adoption of Six Sigma Methodology ${ }^{3}$ and/or its multivariate branches like Total Quality Management (TQM), Supply Chain Management (SCM), and Customer Relationship Management (CRM). Additionally, some firms have either adopted and modified different approaches or designed their own. In the following three sections, we will review the quality-oriented models of the leading Indian ICT firms that specialise in hardware, software and communications infrastructure. In section 2, we review firms like WIPRO and HCL Technologies that specialise in both hardware and software. While Reliance Infocomm that specialises in IT infrastructure has been included in section 3, two other firms, Infosys and Satyam Computer Services, specialising exclusively in software have been reviewed in section 4. Finally, scope for further improvements in innovation process has been briefly brought out by highlighting a few missing elements in the concluding section.

\section{Indian ICT firms specialising in hardware and software}

\section{$2.1 \quad$ WIPRO}

Having a firm foundation in diversified sectors, WIPRO 4 ranks among the top IT services companies globally and is a market leader in India. Armed with good communications services and good infrastructure, WIPRO is one of the few companies that have taken various initiatives towards achieving market satisfaction. To achieve market satisfaction, a rigorous improvement in quality, eliminating defects and providing the market with reliable and timely solutions has been WIPRO's motive. The quality-factor or the Q-factor adopted by WIPRO takes the form of: (i) working continuously to improve quality, remove defects and increase predictability, accuracy; (ii) establishing a well-defined Software Engineering Process Group (SEPG) that aims at establishing standards, defining processes and sustaining process of changes through periodic assessments; (iii) wide use of internet; (iv) a dedicated tools group for software engineering, productivity enhancements; and (v) on-line systems for quality control. To attain this Q-factor, WIPRO has about 3500 members working in teams of five and six on over 292 Six Sigma Methodology projects and 344 Turbo projects facilitated by 74 Black Belts. ${ }^{5}$ In addition to the Q-Factor, the dual role of SEI-CMM and Six Sigma Methodology stand out.

\footnotetext{
${ }^{3}$ Six Sigma Methodology is an approach to achieve near perfection quality for eliminating defects (driving towards six standard deviations between the mean and the nearest specification limit) in any process- from manufacturing to transactional and from product to service.

${ }^{4}$ WIPRO: Corporate Overview 2001, Minds across Borders, Bangalore, India.

${ }^{5}$ For details, see WIPRO - Corporate Overview 2001: Minds across Borders, p. 5.
} 


\section{Six Sigma Methodology}

As is apparent, Six Sigma Methodology has been adopted by this firm with a view to maintaining quality and provides increased opportunities to meet with the market needs. The initiative of Six Sigma Methodology has turned the direction of the firm towards complying with market behaviour through developing and delivering near perfect products and services. By itself, Sigma is a statistical measure of how far a process deviates from its $\operatorname{target}^{6}$. Beginning with identifying the critical business parameters like increasing market satisfaction, new product introduction, improving operating efficiency, the improvement in these areas are identified besides knowing and understanding market needs. Working towards constant improvement in quality, Six Sigma aims at simplifying the existing processes besides striving for their constant improvement. With the above, WIPRO ranks as the first IT services provider in the world to achieve the SEI-CMM Level 5 which is the highest level of quality certification (Wipro: op.cit).

\section{Total Quality Management - Six Sigma Methodology in detail}

WIPRO remains well positioned to offer customers business infrastructure and management. With its green and black belts that are to WIPRO's credit ${ }^{7}$, the firm is also a recipient of the Golden Peacock Award for Innovative Service Quality. Looking into the ultimate goal of improvement in quality with better technology, WIPRO has been aiming at overall improvement in quality of products through good levels of investment in developing a knowledge management infrastructure among its workforce. This has meant efficient knowledge exploitation, expansion and diversification, the building of competent organisation framework and better delivery of customer requirements. Knowledge expansion and diversification also build a strong foundation for technological enhancements that are vital for better compliance of quality standards. Diagram 1 substantiates WIPRO's methodology for achieving TQM.

\footnotetext{
${ }^{6}$ Ibid

${ }^{7}$ Ibid
} 


\section{Diagram 1}

\section{Six Sigma Methodologies for achieving Total Quality Management}

(Source: Wipro: Corporate Overview, 2001, p.15)

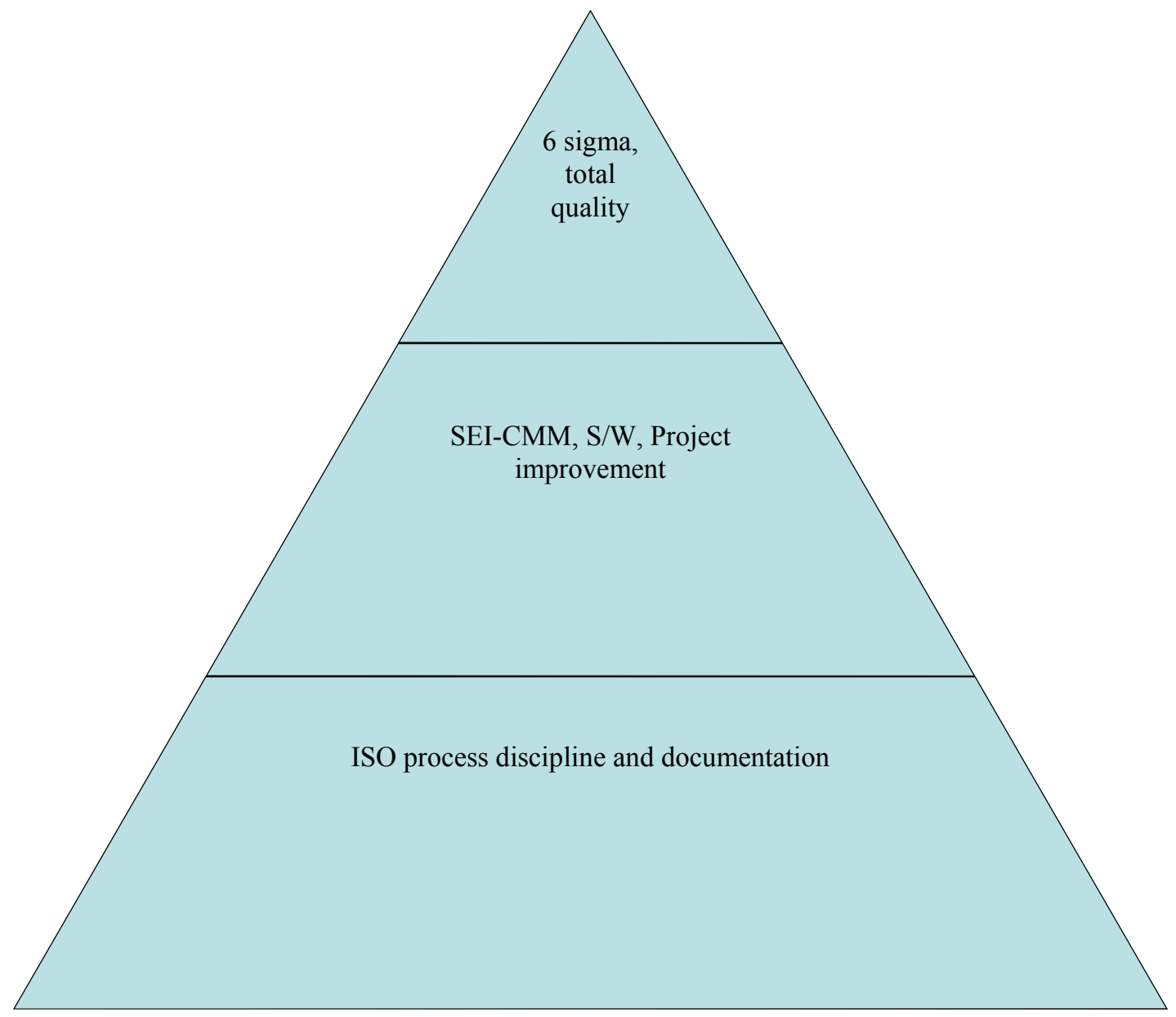

\section{SEI-CMM in brief}

The SEI-CMM for integration focuses on application integration to enhance and improve the software service business. In view of WIPRO's policy towards constant acquisition of new knowledge a relevant model is People Capability Maturity Model (PCMM). Like the knowledge management infrastructure, this PCMM aims at improving people's capability by integrating improvements in processes and the workforce. In short, the PCMM aims at creating world-class people and process quality, in turn developing individual and organisational competencies (Ibid). Therefore, the model adopted by WIPRO presents a case of development through innovation and $\mathrm{R} \& \mathrm{D}^{8}$ by highlighting improving skills of the work force at all levels of the firm. SEI-CMM, being an extension of Six Sigma Methodology, emphasise not only improvement in quality of the product that ultimately enters the market, but also point out the need to improve the quality of the workforce that initiate technological

\footnotetext{
${ }^{8}$ As mentioned earlier, it denotes the research and development activities.
} 
enhancements resulting in better end products. For a better profile of the firm in the market ${ }^{9}$ emphasis is on quality that comes in the form of fewer defects, rigorous quality controls and standards to provide necessary solutions. The well-defined SEPG initiates and establishes standards, defines process and sustains process change by periodic assessments. With over 14,000 people $(11,500$ in IT), WIPRO's model to improve quality rests on one important policy- Applying Thought.

After having highlighted the Six Sigma Methodology and SEI-CMM, the benefits enlisted are as follows ${ }^{10}$ :

(I) Improvement in utilisation of WIPRO Technologies

(II) Reduction of cycle time in manufacturing PCs - hardware

(III) Installation of failures of WIPRO PCs reduced significantly

(IV) $25 \%$ of customer breakdown calls closed on telephone at WIPRO Infotech

(V) Accurate cost estimation for fixed price projects in WIPRO Technologies

(VI) Service partner satisfaction index increased from $44 \%$ to $75 \%$ at WIPRO Infotech.

As earlier mentioned WIPRO has the unique distinction of being the first recipient of SEI$C M M$ Level 5- the highest attainable level ${ }^{11}$. Additionally, WIPRO has also come out with a new model called SEI-CMMi in October 2000. In brief it is a unified model addressing software development, system engineering and integrated product development. WIPRO has been maintaining its stand of pursuing world class quality and building its credibility in the market.

\subsection{HCL Technologies Limited}

HCL Technologies Limited is a global IT services company offering software consulting development, maintenance and training services as well as maintaining the hardware division. With rich experience in designing and implementing business applications, HCL has gained a reputation for working closely with all its clientele. Its expertise has enabled HCL to deliver robust, secure, easily maintainable applications, providing its customers with many benefits including: (i) resource management; (ii) competitive; (iii) budgetary. Expertise of HCL that includes $S C M^{12}, E A I^{13}, E R P^{14}$, and $C R M^{15}$ have continuously added value to the clients by delivering high quality, cost effective solutions through total quality programmes. The dynamic, and flexible Quality Management System (QMS) that has evolved over many years is compliant with ISO9001 standard and SEI-CMM. HCL has also achieved Level 4 and Level 5 of SEI-CMM.

\footnotetext{
${ }^{9}$ Sundbo (1998), pp.105-158

${ }^{10}$ WIPRO-Corporate Overview, p.23

11 Source: Op.cit

${ }^{12}$ Commonly known as Supply Chain Management, HCL with its SCM solutions expertise and a background in Enterprise Resource Planning (ERP) gives very significant expertise in process consulting as well as product configuration besides system configuration. More information about this can be had from HCL web site link that is given as follows: http://www.hcltechnologies.com/artdisplay.asp?cat_id=98\&art_id=368

13 Also known as Enterprise Application Integration, this is believed to lay a strong foundation to technology infrastructure that links business applications into one unified system such that data can be shared throughout the organisation. This $E A I$ has an impact on efficiency, productivity, speed and performance.

${ }^{14}$ Enterprise Resource Planning which is also connected to the supply chain, CRM applications and the like ensures that any organisation adopting the ERP would have a competitive edge.

${ }^{15}$ Usually referred to as Customer Relationship Management in its extended form this focuses on rendering customer-oriented application package. With talented project managers, consultants and business analysts in the team, these dedicated sets of members have helped create focussed front office suites for he clients.
} 


\section{Growth towards achievement of quality}

Commencing with a meeting between quality coordinators and team members of the project all of whom know the market needs to ensure product and process quality during a project, a software quality assurance engineer (SQA) monitors the progress of the project and its status periodically and liaises with the customers through pre-defined conference calls. Clearly for HCL Technologies the journey of quality began with ISO9000 certification of the software development centre (SDC) before quality control scrutiny in SEI-CMM Level 4 followed by Level 5, expounding its determination to eliminate defects and manage the constant changes taking place in technology.

\section{ISO9001 Certification}

This was the first step taken by HCL towards the achievement of quality. The journey for the improvement of quality began in 1995 in line with ISO9000:1994. Starting their process definitions complying with ISO standards, HCL received its first certification in the year 1997.After having moved up the quality ladder, SDCs today are also certified ISO9001:1994n, with many achieving re-certification. Improvements in quality have been proved by the way of ISO9000:2000 certification. The underlying idea of ISO certification is to enable all the SDCs to ensure on-time delivery of projects with few or no defects.

\section{SEI-CMM Model}

SEI-CMM is the key element that describes an effective software process. Covering planning, engineering, managing software development process and its maintenance, SEI-CMM is the benchmark by which an organisation can improve its software. Representing a commonsense engineering approach it is just a step forward in software improvement.

Quite clearly HCL Technologies has adopted a step-by-step approach for achieving quality in software development process. Also known as the five levels of software process maturity, these include the following:

- INITIAL: Here the software process is characterised as ad hoc with very few processes being defined. Success depends entirely on individual effort

- REPEATABLE: Basic project management techniques are established to ascertain costs and functionality.

- DEFINED: Management and engineering processes are documented, standardised and integrated into a standard software process for clarification by the organisation.

- MANAGED: Detailed measures of the software process and product quality are collected, which are quantitatively understood and controlled.

- OPTIMISING: At this final stage, continuous process improvement is enabled by qualitative feedbacks from the process itself and from resulting innovative ideas and technologies.

The diagrammatic representation of the five levels discussed above is shown below. 


\section{Diagram 2}

Five Levels of Software Process Maturity

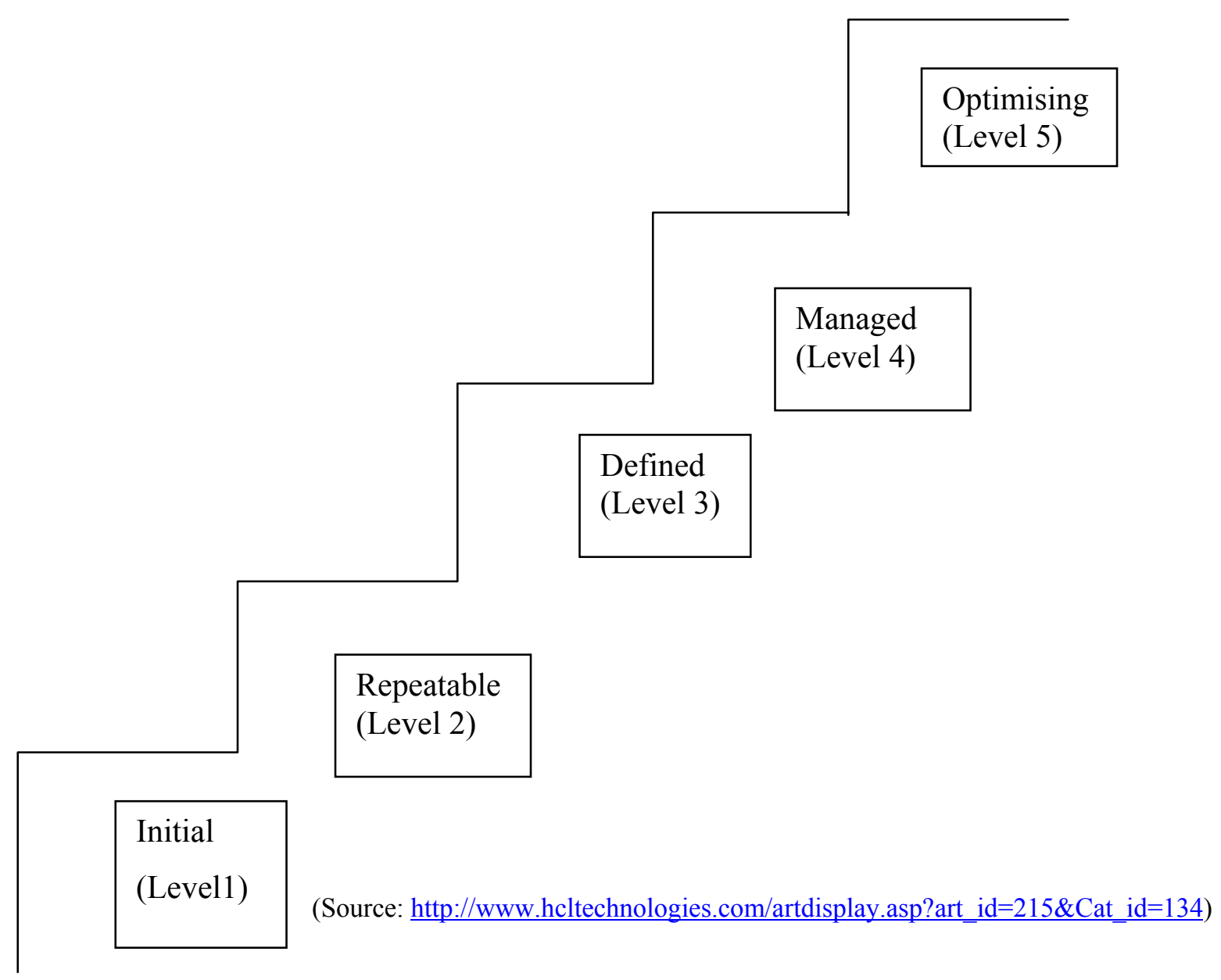

Diagram 2 brings out the step-by-step approach adopted by HCL Technologies for achieving quality in the software development process. Like some its counterparts in the Indian ICT industry, HCL Technologies that has achieved SEI-CMM Levels 4 and 5 is working incessantly towards eliminating defects and improving the overall quality of its products and services.

\section{3. $\quad$ Firms specialising in ICT infrastructure}

\section{Reliance Infocomm}

Being a part of the Reliance Group of industries, Reliance Infocomm is India's leading telecommunication infrastructure provider through the provision of broadband communication infrastructure. Working towards improving the existing communications infrastructure with the most advanced technology, this process includes transformation from a normal public service telephone network to a high speed broadband network and from plain voice telephony to virtual network. The latest and the best telecommunication infrastructure are being achieved thus: 
- Build a comprehensive network covering all the population of varied region from rural areas to a high-tech city

- International gateways to cover the rest of the world

- High-quality service even to the remotest area

- $100 \%$ digital state of art infrastructure. ${ }^{16}$

With technology and communication being a dynamic than a static sector, Reliance Infocomm is synonymous with effective R\&D supporting knowledge intensity. Reliance's strategy to sustain improvement in communication infrastructure is supported by its Six Point Agenda $^{17}$ :

- Revolutionise asset productivity

- Build a strong intellectual property rights ${ }^{18}$

- Increase pace of new product introduction

- Build new product platforms

- Commercialise new licenses

- Develop future opportunities through discovery research

Knowing the importance of knowledge transfer, interactive learning and knowledge spillovers that are vital to develop opportunities for future research, Reliance's Product Application and Research Centres (PARC) have proposed the creation of virtual network to promote knowledge-sharing with customers and end users. This approach has the benefit of knowing a continuous basis what the customer's ideas are for any product enhancement or modification. Emphasizing quality, Reliance Infocomm has carefully-designed systems that are available on the corporate intranet to ensure faster decision-making about products and their better quality. Advanced technology systems, advanced analytical instruments at sophisticated quality assurance laboratories are key elements of Reliance's quality drive. With 29 ISO 9000 certificates confirming the firm's commitment to improving its quality, the importance of constant improvement is made available by the $T Q M^{19}$ implementation team. Also being a recipient of the Golden Peacock Award for innovation management, this constant improvement through advanced technology, on-line communications and information exchange, quality circles which includes Six Sigma Methodology, Six Point Agenda, CRM, quality chain audits, and quality reviews helps Reliance achieve its goal of Total Customer Satisfaction.

Quite clearly, the PSPD model of Infosys and Six Point Agenda of Reliance both highlight the importance of market sustainability through profit maximisation that follows quality improvement. The major difference is that while Infosys avoids concepts such as total customer satisfaction, exchange of information with the end user, and transfer of ideas which resemble ILSs concept (Crevoisier, 1999), Reliance Infocomm uses exactly these precepts to help improve the quality of its products and thence its sustainability (pp.61-79).

\footnotetext{
${ }^{16}$ This state of the art is said to be capable of serving terabits of data per second

${ }^{17}$ Source: Reliance Industries: Annual Report 2000-2001, pp.48-49

18 This is commonly known as IPR and will as stated in the coming pages

19 The abbreviation TQM stands for Total Quality Management that insists on the constant improvement in quality for the better satisfaction of the end user.
} 


\section{Diagram 3}

\section{Total Customer Satisfaction through improved Quality}

\section{Step1}

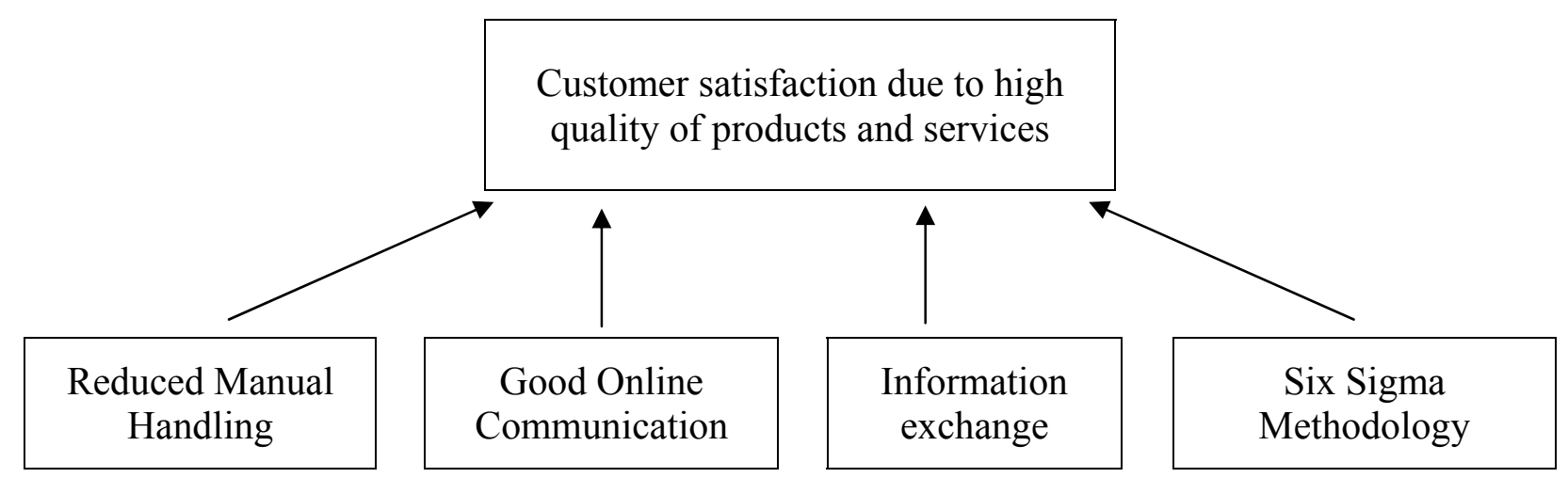

Source: Reliance Industries Limited: Annual Report, 2001, pp. 48-49

Step 2

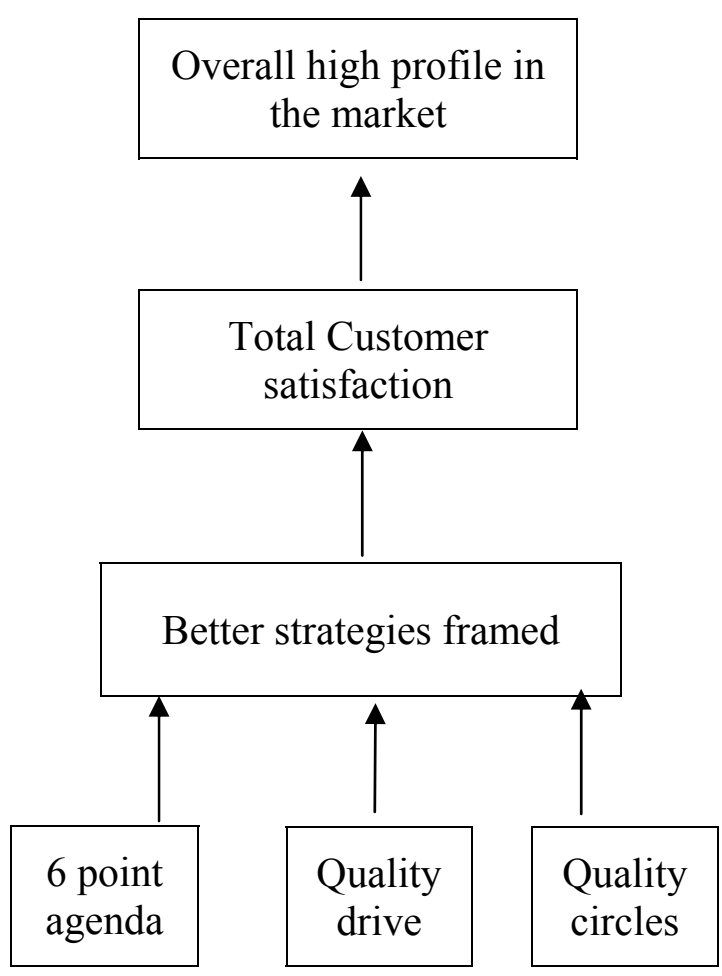

Source: Reliance Industries Limited: op.cit 


\section{Firms specialising only in software services}

\subsection{Infosys}

With the Indian software industry growing rapidly, India has been considered the most mature region for IT offshore work. By the way of taking advantage of IT and IT-related services, risk and risk management aspects are inherent. Long term interest in market sustainability and a better control over the market along with stronger relationships with customer calls for competitive strengths and framing of proper strategies ${ }^{20}$. In this regard, there is a strong perception about Indians being technically strong but poor on the management side. This questions the capacity to frame proper strategies and policies ${ }^{21}$. Being quite established in the software area of Indian ICT industry in India, Infosys has identified major areas threatening the growth of Indian ICT industry and has stressed on the need to develop an appropriate business model. A few essentials of these business models $\operatorname{are}^{22}$ :

(I) The ability to understand clients' business, introduce credible technology that offers credible business solutions. Here the effective and interactive roles of ILSs gain prominence regarding understanding market behaviour, requirements and giving solutions accordingly.

(II) Stressing on the need to improve infrastructure in the country, Infosys emphasizes that global delivery capability for any firms comes in with adequate proper infrastructure that is critical for providing high-quality, cost-effective solutions. In India, the central government has been taking adequate measures to improve market infrastructure in the country, especially the communications infrastructure such that there is timely flow of solutions. Related to this is the ability to attract high-talents and able professionals such that growth of the firms and the entire industry is ensured.

(III) Along with the need for proper information and the establishment of ILSs, another essential for the business models as mentioned by Infosys is that of a clientfocussed organisational structure which again calls for the applicability of strategy theory. Focussing on improving the market profile through a proper understanding of the market, to Infosys, the business models should have well-planned imagebuilding efforts such that establishing control in the market becomes a lot easier.

In addition to the above mentioned essentials, Infosys has been working on moving up the value chain. Although this concept is not dealt with in detail here, a diagrammatic representation has been given to illustrate this concept of value chain ${ }^{23}$.

\footnotetext{
${ }^{20}$ Source: Infosys- Moving up the value chain, p.5

${ }^{21}$ Source: Ibid

${ }^{22}$ Source: Infosys - Managing enterprises in challenging times, pp.4-5

${ }^{23}$ Source: Infosys - Moving up the value chain, pp.9-10
} 
Diagram 4

\section{Concept of value chain by Infosys}

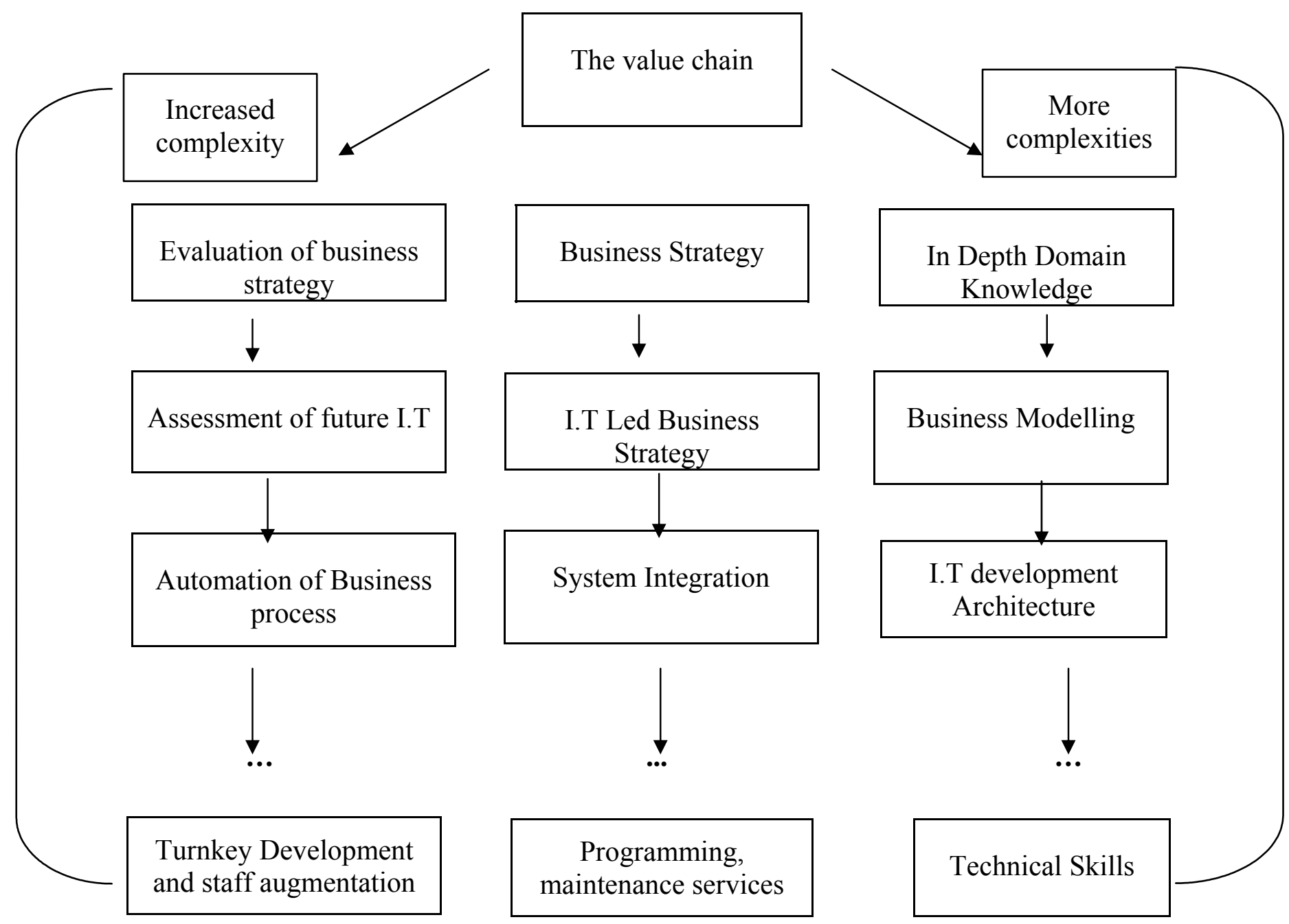

Along with the concept of value chain, Infosys aims to improve its overall performance to maintain its control over the market. The firm's business model rests on four main elements: (1) predictability; (2) sustainability; (3) profitability and; (4) the derisking. Also known as the PSPD Model, it primarily evaluates the revenue aspect of the firm. Focussing on long-term relationship with clients, the model also invokes the search for competitiveness. By way of explaining elements in greater detail, predictability and sustainability aspects of the model are intertwined with the revenue likely to be earned by the firm. Along with the third element called profitability, the last element of the PSPD model-derisking-provides the company with strength and stability to react effectively to changes in the business environment. With the above, the advantages and disadvantages of the PSPD Model include: (see Infosys: Risk Management Report, 2001, p.82). 


\section{Advantages}

- Higher margins

- Higher predictability of revenue

- Stronger relationship

- End to end service providers etc to name a few

\section{Disadvantages}

- Different sales and marketing skills

- Higher investment in a particular client

- Acquiring new skills in solution delivery.

Relating to the last point on acquiring new skills in solution delivery, Infosys has been working towards delivering high-quality software services to its clients within the budgeted time and cost. To achieve this, the company built a consulting team to restructure the organisation by delineating different compensation models, different performance metrics, training and knowledge-sharing to improve competency levels, and the forming of an integral group to closely monitor dynamic technology trends.

Generally, a comprehensive and integrated risk-management framework forms the basis of all risk-taking efforts of the company. Formal reporting and control mechanisms ensure the availability of timely information and facilitates proactive risk management. These mechanisms are designed to cascade down to the level of line managers so that risks at the transacttional level are identified and all possible steps are taken towards mitigation in a decentralised fashion. By focusing on current and future positions of growth, key factors includes changes to be brought into line with the organisational framework of a firm, building its knowledge base, building and enhancing products, changing and acquiring market position.

The adoption of some quality models like SEI-CMM has meant proper identification of risks at the right time and measures to be taken to mitigate them at the initial plan phase itself. Infosys is also a recipient of SEI-CMM Level 5, a level that only few companies have realised (see Infosys: Risk Management Report, 2001, p.86). Studies from various reports of Infosys reveal that this firm also plans to bring out a risk management guideline detailing how various risks can be identified at the initial plan phase itself and how they can effectively be mitigated. A database of such information would focus one's attention on the key improvement areas. With the firm being primarily focused on software services (unlike WIPRO that also has a hardware wing for its IT division), Infosys has been enhancing the process of quality in other enterprises, to align it with their other organisational processes using Six Sigma Methodology and Malcolm Bridge Quality Framework. Another Infosys methodology InFlux also gains prominence (see http://www.infosys.com/innovation/influx.asp) at this juncture.

\section{InFlux}

This yet another Infosys methodology InFlux is an integrated framework helping in determining the impact of new initiatives and defining IT solutions for these new initiatives. With its business modelling framework based on digital world concept, InFlux has become an integral part of Infosys to realise some of the intertwined complicated strategies and corresponding technology-driven initiatives (Diagram 5). 


\section{Diagram 5}

\section{InFlux Business Modelling by Infosys}
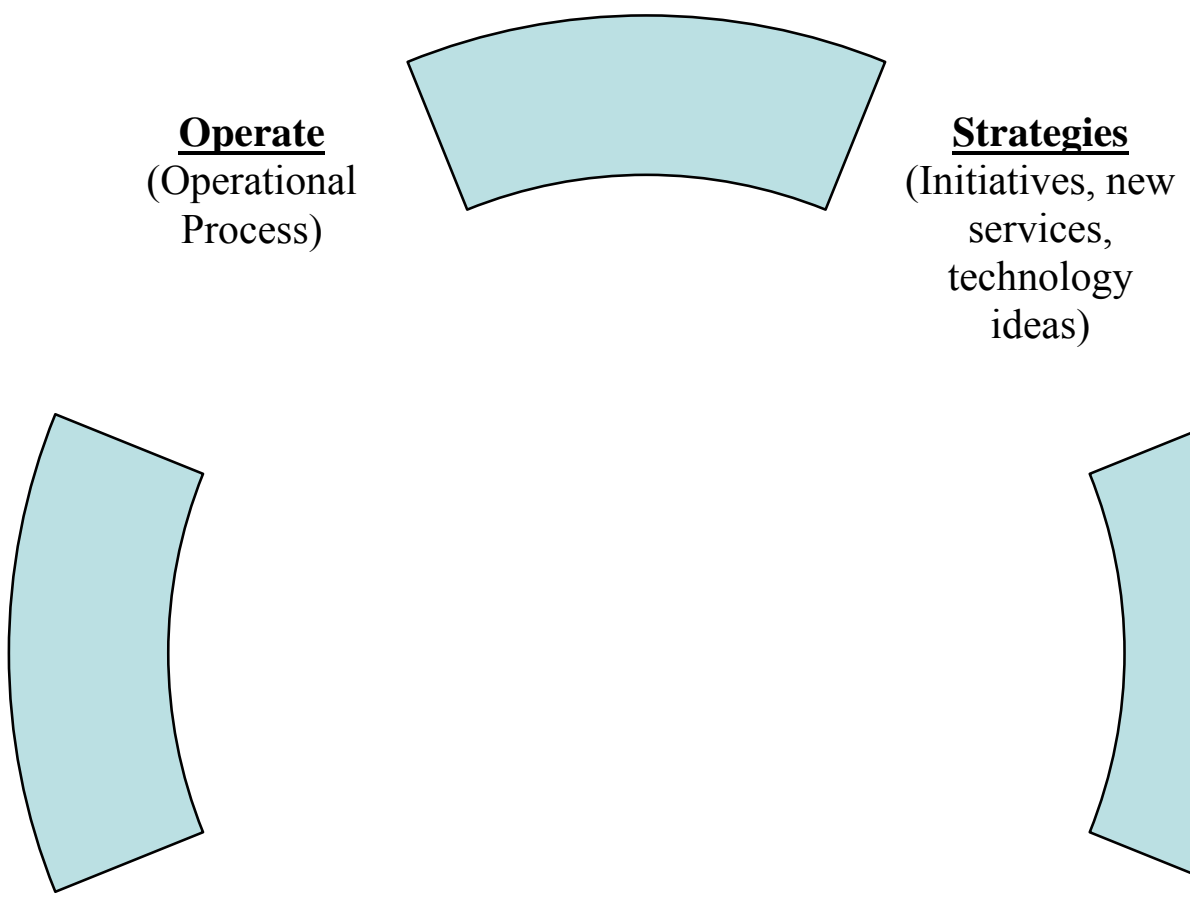

Implement

Define

(I T Solutions)

(New Business

Models, IT

solution

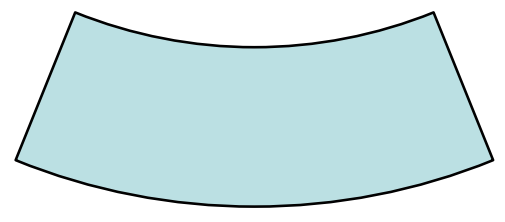

definition)

Source: http://www.infosys.com/innovation/influx.asp

Clearly Infosys has progressed from a traditional model of body-shop, cost-plus pricing, etc to an emerging model that comprises of: (i) higher levels of engagement; (ii) value-based pricing; (iii) selected alliances with major global pricing; and (iv) international sales and marketing presence. As software services firm, Infosys continues to evolve business models that work towards the overall improvement in quality of end products. In line with the strategy theory, Infosys has been working towards client satisfaction, gaining expertise in various areas of software development like consulting, building in-house expertise, identifying the key growth areas, achieve technology expertise for which R\&D and innovation play a vital part. By the way of creating the knowledge base, Infosys has people researching different technology areas and trying to build competency.

From the above, it is clear that the primary motive of this firm is to work towards improvement in quality of the products and services that enter the market in general such that sustenance in the market is easy with higher revenue 


\subsection{Satyam Computer Services Limited}

Being a global consulting and IT services-related firm, Satyam began with strategy consulting and solution implementing for its IT clients. As a diverse end-to-end IT solutions provider, Satyam today offers expertise that is focussed on helping customers to successfully re-engineer and re-invent their businesses for an ever-changing market place, with the final objective of giving clients a competitive edge With over 9,700 dedicated IT professionals in the Satyam team, the IT solutions have resulted in technology-intensive transformations that have complied with the most stringent quality standards. Having a strategic technology and marketing alliance with over 60 leading companies, the need to engender technological expertise brings customers a range of solutions and products that are superior in quality which enhances productivity and competitiveness.

Major contributions towards building Quality:

- Pioneers in Offshore Development: Satyam has pioneered in Offshore Development Centre Model for software delivery through gathering the skilled workforce (available in plenty in India).

- Establishment of development Centres in India: The concept of setting up development centres to outsource IT initiatives was originated by Satyam and these are located in various Indian cities.

- eSCM: A quality model for ITES/BPO ${ }^{24}$ has been attained by working in close coordination with Carnegie Mellon University. Satyam has developed a quality model that defines standards for ITES/BPO.

- Rightsourcing Model: Satyam has also introduced a unique delivery model called Rightsourcing model that provides optimum combination of off-site, onsite and onshore delivery.

\section{Quality culture at Satyam}

The culture is one of effective communication and knowledge-sharing across the organisation via the exchange of information, ideas, and solutions. Quality for Satyam began with ISO9001 certification, duly followed by TICK IT and recently surveillance on the quality aspect by $B V Q I^{25}$. Quality is a continuous process that is emphasised in the firm's activities.

ISO9001: 2000 Certified Organisation in the World

Becoming the first organisation in the world to be assessed by BVQI, Satyam was found to be in accordance with the requirements of the new ISO9001:2000 International Standards under the TICK IT scheme.

\section{SEI-CMM}

Satyam was one of the first 10 companies in the world to attain an organisation wide SEICMM Level 5 assessment; the most sought-after quality standard in the world, instituted by Carnegie Mellon University, and it was achieved at the first attempt. With regards to software

\footnotetext{
${ }^{24}$ This abbreviation stands for Business Process Outsourcing.

${ }^{25}$ The long form of this is Bureau Veritas Quality International that conducts periodic checks and thence stresses on the quality of the products and services.
} 
process consulting (SPC) services and software process improvement, the preferred frameworks used by Satyam are SEI-CMM, ISO, and SPICE. These models are chosen appropriate to software process improvement in a systematic manner. On the whole Satyam is flexible, interactive and oriented towards customer's business objectives, priorities and significance.

\section{IMC Bajaj National Quality Trophy for 2001}

Satyam received the Bajaj National Quality Trophy in 2001. This award was instituted in 1997 by the Indian Merchants Chamber and is similar to the Malcolm Bridge National Quality Award given to American companies. This award recognised understanding of requirements for business excellence and sharing of information on successful performance strategies.

It is worth noting that a number of models and frameworks are available to provide guidance for designing and implementing software process improvements thereby rendering improved quality services. Diagrammatically,

\section{Diagram 6}

Satyam and its focus on Quality

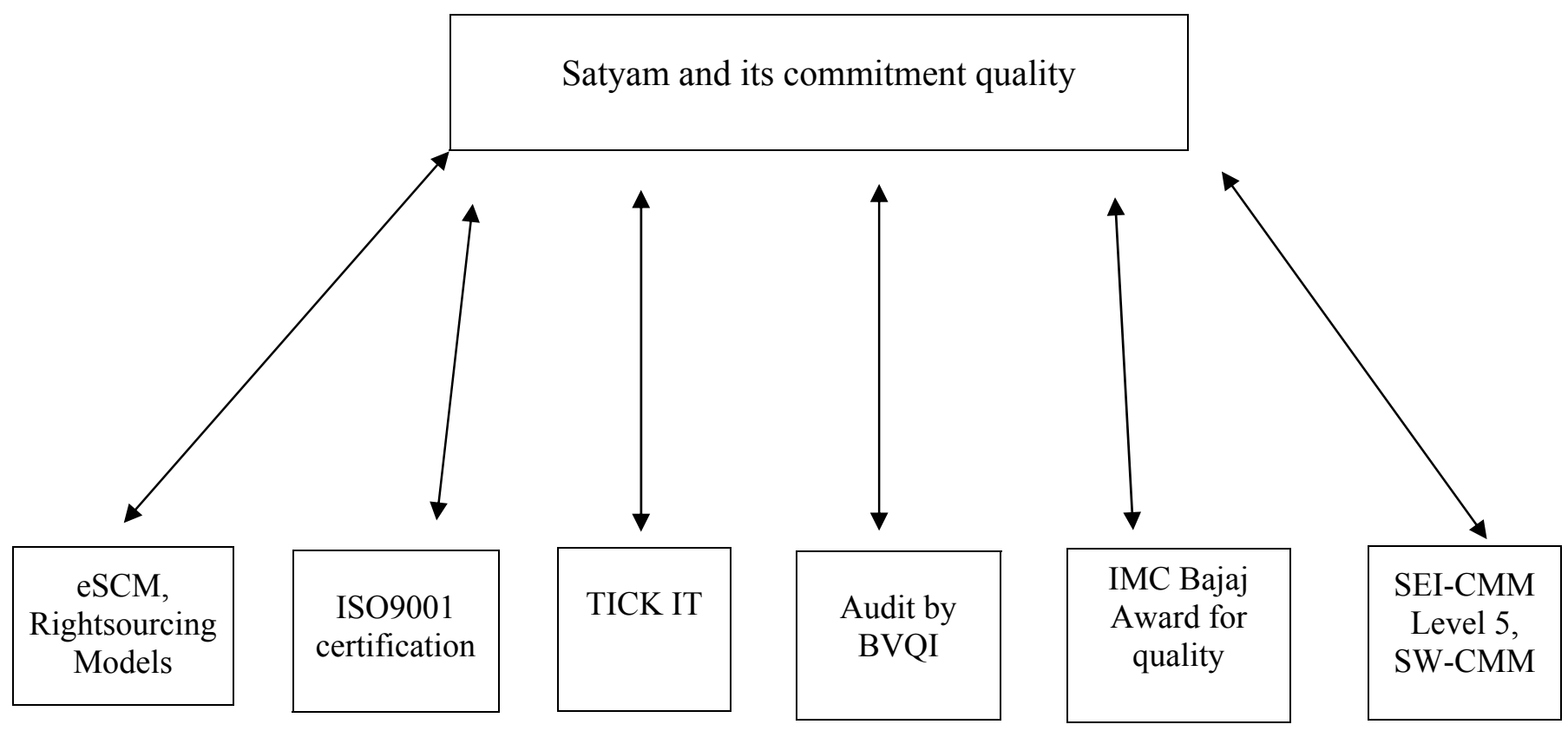




\section{Diagram 7}

\section{Model Driven Consulting ${ }^{26}$}

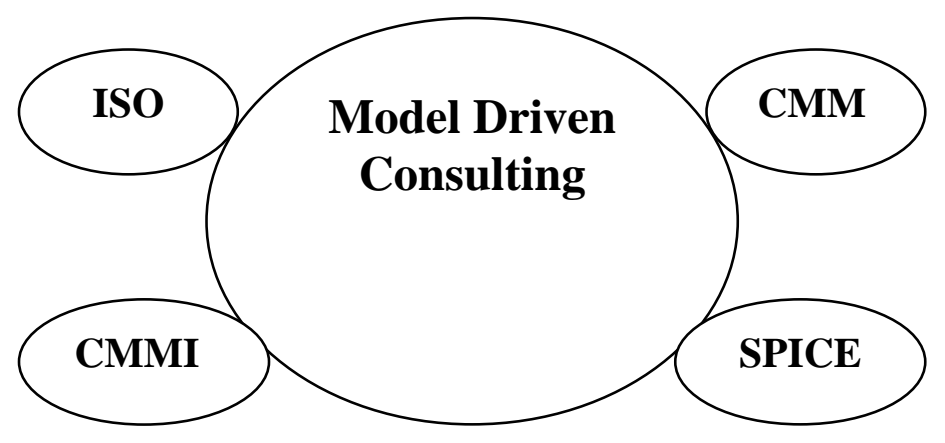

Clearly, these various forms of frameworks like SW-CMM, SPICE, and CMMi need to be chosen correctly and interpreted in a systematic manner in an organisation. Concentrating on quality, Satyam has developed: (i) eSCM in collaboration with Carnegie Mellon University.

\section{eSCM Consulting and Engagement Model}

The eSourcing Capability Model (eSCM) is the first standard for outsourcing service providers and has been developed by Carnegie Mellon University to help the service providers develop and improve process capability from execution to completion phase, and to establish, manage and improve relationship with clients, as well as supporting basic functions of technology, organisational knowledge. eSCM provides clear set of guidelines to outsourcing service providers by focussing on organisational attributes for the workforce, and technology and knowledge. eSCM is also accompanied by multiple appraisal and evaluation methods that would enable users to maintain and enhance client relationships and deliver services to clients within their current capabilities. (With Carnegie and Mellon University being the pioneer of the CMMs to assess the quality of a firm, it is also worth noting that the models that come under the banner of SEI-CMM family are normally used to assess the quality rating of the firm.) Following the ongoing developments on various quality models, the researchers at Carnegie and Mellon University along with researchers and engineers at Satyam worked on eSCM Model for about a year. Although a number of modules for evaluating quality do exist, eSCM Model is believed to contain those practises that are not available in other models. $e S C M$ is found to address many challenges that outsourcing service provider $^{27}$ and related enterprises are bound to face. The key reasons why outsourcing contracts are unsuccessful are that of difficulty in measuring cost and performance, absence of clear control points and deliverables not meeting with quality expectations;. eSCM is assumed to give solution to these problems.

\footnotetext{
${ }^{26}$ For more details on the diagram, please see http://www.satyam.com/solutions/s tqc serv.html

27 The abbreviation is OPC for simplicity.
} 
The build phase

The range of services is based on the proven that is also known as the Build, Operate and Transition Engagement Model (BOT) and includes:

- Process Analysis: A detailed report includes:

- Extent of compliance of their processes with respect to eSCM

- Strengths that can be leveraged towards the achievement of business goals

- Areas requiring improvement in order to meet business goals.

- Strategic Planning: This is a blueprint for a successful process improvement initiative. Strategic initiative planning has been developed for achieving and identifying process improvement goals based on business goals and process analysis report of the organisation.

- Process Design: Conducted using a predefined methodology, here the involvement of the organisation's personnel is the key to success.

The operate phase

Under this phase, the focus includes:

- Process Deployment: Issues related to change management for smooth deployment, appropriate process automation tools, and identification and collection of appropriate process measures for the organisation.

- Process Verification: Checks for compliance with eSCM, and varies according to its stage in the engagement life cycle.

\section{The transition phase}

This means successful implementation of a process improvement initiative so as to sustain process capability and ensure a continuous improvement. During transition phase, insights into the capability and performance of key processes are gathered and all process improvement measurements and trends are appropriately disseminated.

\section{Risk Protection Strategy}

Using all the inputs above mentioned to plan an entire project and with management tools refined over many improvement projects, prepare a realistic improvement plan (Diagram 8). 


\section{Diagram 8}

\section{Risk Management Strategy}

\section{Organisational Perspectives}

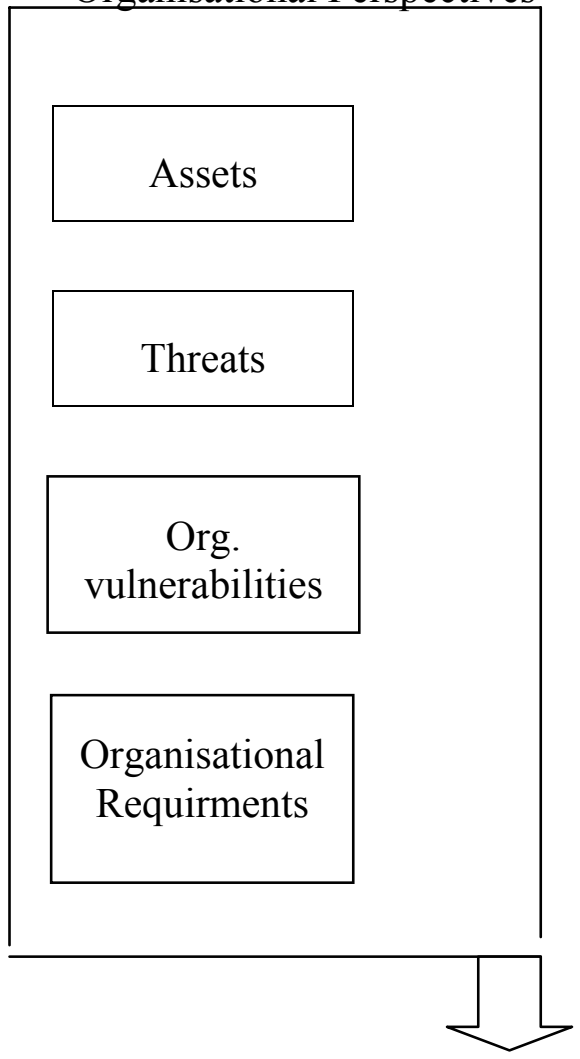

Technological Perspectives

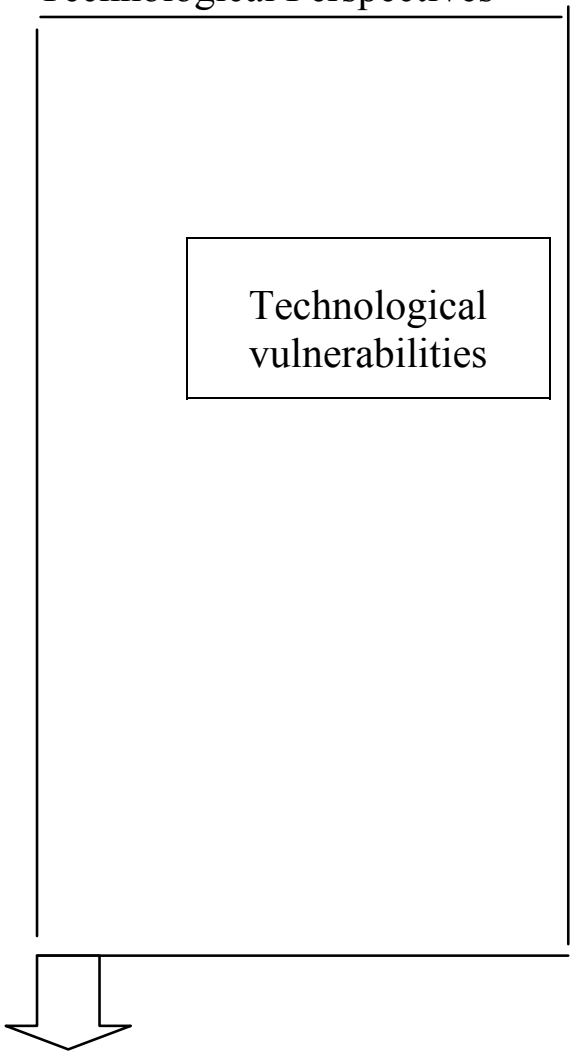

\section{Risk Protection Strategy}

Source: http://www.satyam.com and Information Security Management Systems

Along with this risk protection strategy, the Information Security Management (ISM) and Security Level Management (SLM) also gain prominence. While ISM denotes the protection of information assets through policies, procedures and technologies, the SLM services are specifically designed to develop and implement solutions to problems pertaining to satisfying clientele base.

\section{The Core Values of Satyam:}

Satyam's core values are expressed in the way the teams are built and the way in which they operate so as to achieve results. These values are the guiding elements for the organisation as a whole, and are based on the internal strengths of the firm (Diagram 9). 


\section{Diagram 9}

The core values of Satyam

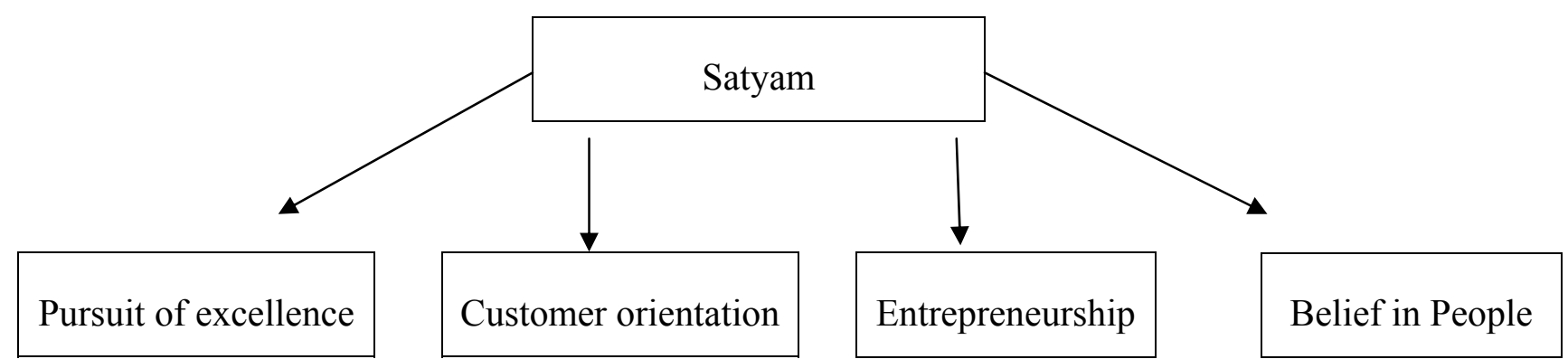

Source: http://www.Satyam.com/aboutSatyam/a philosophy.html

Further to Diagram 9, core values are as follows ${ }^{28}$ :

- Pursuit of Excellence: Adhering to stringent quality processes that meet with the international standards, these quality processes are constantly monitored to achieve excellence.

- Customer Satisfaction: Catering mainly to corporate clients, Satyam is focussed on competitiveness and meeting with their needs such that sustenance is easier.

- Entrepreneurship: Various programmes help associates create tangible values and constant encouragement is given to these associates to convert their ideas into market values that build the spirit of entrepreneurship.

- Belief in People: The true strength lies in its associates.

Bringing the discussion together, the model adopted by Satyam insists on:

- Early identification of any problem

- Take appropriate steps to control that problem

- Bring about technological improvements

- Ensuring improvement in quality is a continuous process and

- Training professionals to the required level to enable them to comply with required quality standards.

\section{Conclusion:}

Going by the strategy theory, the strategies and policies play an important role in the ultimate advancement of the technology sector especially in developing countries like India that are undergoing a technological change. This paper has expounded on the role of the major Indian ICT firms in improving quality of their products and services to enjoy greater control and sustenance in the market. The following Table-1 below shows their product/services specialisation as well as their quality models/approaches adopted.

${ }^{28}$ Refer: http://www.satyam.com/aboutsatyam/a philosophy.html 
$\underline{\text { Table } 1}$

\begin{tabular}{|c|c|c|}
\hline Name of the firm & Specialisation area & $\begin{array}{c}\text { Firm's quality } \\
\text { approach/model }\end{array}$ \\
\hline WIPRO & Hardware, Software & $\begin{array}{c}\text { 6Sigma:SEI-CMM, CRM, } \\
\text { TQM }\end{array}$ \\
\hline Infosys & Software \& related services & $\begin{array}{c}\text { PSPD model, Value Chain, } \\
\text { 6Sigma: SEI-CMM, Influx }\end{array}$ \\
\hline Reliance Infocomm & Hardware-IT infrastructure & $\begin{array}{c}\text { Quality Circles, 6 Point } \\
\text { agenda, Quality Drive, } \\
\text { Process, TQM }\end{array}$ \\
\hline HCL Technologies & Software \& related services & $\begin{array}{c}\text { 5Levels of S/W Process } \\
\text { Maturity, CRM, EAI, SCM, } \\
\text { ERP, SQA, SEI-CMM }\end{array}$ \\
\hline $\begin{array}{c}\text { Satyam Computer } \\
\text { Services }\end{array}$ & Software \& related services & $\begin{array}{c}\text { eSourcing Capability Model, } \\
\text { Engagement Model, SEI- } \\
\text { CMM, SW-CMM }\end{array}$ \\
\hline
\end{tabular}

Realising the need to improve the profile in the market, most of the firms in the Indian ICT industry irrespective of their size, have now begun to understand the importance of improvement in quality of products and services entering the market. Top-level management of the major Indian ICT firms specialising in different areas of the ICT industry have made their own teams identify and understand clientele needs and have designed various pathways towards TQM. However, no longer being confined only to established firms, the transfer of technology and ideas, and diffusion of market knowledge become necessary for newlyemerging firms to consolidate the market. Better R\&D and innovation activities are expected to strengthen the capability of a firm to easily sustain in the market through increased quality control and derisking. All these are clear indicative not only of the increasing applicability of strategy theory, but also of the increasing prominence given to the exchange of ideas. This increases the scope of this paper by encompassing two important statements namely: (i) whether firms in Indian technology industry have taken the outcome of innovation activities seriously; and (ii) whether the firms only aim towards improving the quality of their products for sales maximisation abroad during the post economic liberalisation period of India's economic growth. Assuming the former statement to be true, the establishment of interaction and learning sites (ILSs) is vital for the betterment of the industry (Crevoisier, 1999). These ILSs serve as joints where interaction between firms of varied sizes takes place creating transfer and diffusion of knowledge.

It is clear from the ICT firms discussed above that there are still some important issues that appear to have been overlooked. These missing elements, namely (i) absence of proper marketing element - right product reaching the right kind of consumer; (ii) absence of localised strategies, policies - the need for market-based strategies such that penetration of technology is easier in the local markets; (iii) absence of prior testing of finished products with consumer, implying the importance to opinions got from the end user about the newly developed product or service all of which further ascertains the need for the establishment of ILSs in every regional State in India through which the overall development of the Indian ICT industry can expected to be achieved. 


\section{References}

Chakraborthy, C. and D.K. Dutta (2003), "Indian Software Industry: Growth Patterns, Constraints and Government Initiatives", edited by Raghavendra Jha, Working Paper. Palgrave-Macmillan, India

Crevoisier, O. (1999), "Innovation and the City", in Malecki, E. J., and P. Oinas, "Making Connections - Technological Learning and Regional Economic Change”, Ashgate Publishing Company, U.K

Department of Telecommunications, Ministry of Information Technology, Government of India, Website: www.mit.gov.in

ESCAP (Economic and Social Commission for Asia and the Pacific) (1999), Economic and Social Survey of Asia and the Pacific 1999, Part 2, United Nations, New York

Information Technology Act, 2000, Ministry of Information Technology, Government of India, Website: www.mit.gov.in

Infosys, (2002), “Managing Enterprises in Challenging Times”, Bangalore, India, pp.1-141, Website: www.infosys.com

(2001) PSPD Model, Bangalore, India, Website: http://www.infosys.com

(2001) Risk Management Report, Bangalore, India, Website: http://www.infosys.com

(2001) The Indian Software Industry: Moving up the Value Chain, Bangalore, India, pp.1-25, Website: http://www.infosys.com

Kumar, N. (2001), "Indian Software Industry Development-National and International Perspective", Economic and Political Weekly, Vol.36, No.45 (November 10-16), India

Malecki, E. J., and P. Oinas, "Making Connections - Technological Learning and Regional Economic Change”, Ashgate Publishing Company, U.K

Mytelka, K. L. (1999), “ Competition, Innovation and Competitiveness: A Framework For Analysis" in Mytelka, K. L. (1999), "Competition, Innovation and Competitiveness in Developing Countries", Development Centre Studies, Development Centre of the Organisation for Economic Co-operation and Development, OECD Publications, Paris, France, pp.15-33

Mytelka, K. L. (1999), "Competition, Innovation and Competitiveness in Developing Countries", Development Centre Studies, Development Centre of the Organisation for Economic Co-operation and Development, OECD Publications, Paris, France

National Task Force on Information Technology and Software Development, India, Web site: www.it-taskforce.nic.in

Reliance Industries Limited (2000-2001) Annual Report, Mumbai, India, pp.48-49

Satyam Computer Services, Information Security Management, Website: http://www.satyam.com

Service Level Management, Website: http://www.satyam.com

Sekhar, A. (2004), PUDSS Model and Indian Economic Development, Working PhD Thesis, Dept. of Economics, School of Business and Economics, The University of Sydney, Australia, pp.67-114 
Shibulal, S.D. (2002), "Back to the Basics: Imperatives for the Technology Services Industry", in Infosys, (2002), "Managing Enterprises in Challenging Times”, Bangalore, India, pp.4-5, Website: www.infosys.com

Singh, L. (2000), “Technology Spillovers and India's Industrial Growth", The Indian Journal of Economics, Vol.L30, No.318 (January), Part 3, Millennium Numbers, University Of Allahabad, India, pp 318-331

Smadja, C. (2002), "Leading the Globally Competitive Corporation", in Infosys, (2002), "Managing Enterprises in Challenging Times", Bangalore, India, pp.6-7, Website: www.infosys.com

Sundbo, J. (1998), “The Theory of Innovation, Entrepreneurs, Technology and Strategies”, Edward Elgar Publications, Cheltenham, U.K

WIPRO: Corporate Review, (2001), Minds across Borders, Bangalore, India, Website: www.wipro.com

\section{Websites}

http://www.hcltechnologies.com/artdisplay.asp?cat_id=24

http://www.hcltechnologies.com/artdisplay.asp?cat_id=25

http://www.hcltechnologies.com/artdisplay.asp?cat id $=26$

http://www.hcltechnologies.com/artdisplay.asp?cat $\mathrm{id}=27$

http://www.hcltechnologies.com/artdisplay.asp?cat $\mathrm{id}=62$

http://www.hcltechnologies.com/artdisplay.asp?art_id=215\&Cat_Id=134

http://www.hcltechnologies.com/artdisplay.asp?art id=216\&Cat id=134

http://www.hcltechnologies.com/artdisplay.asp?cat_id=247

http://www.hcltechnologies.com/artdisplay.asp?cat_id=98\&art_id=368

http://www.infosys.com/innovation/influx.asp

http://www.ril.com

http://www.satyam.com

http://www.satyam.com/aboutsatyam/a philosophy.html

http://www.satyam.com/aboutsatyam/a pioneeringeffort.html

http://www.satyam.com/quality/q_philosophy.html

http://www.satyam.com/quality/q_achivements.html

http://www.satyam.com/solution/s tqc_serv.html

http://www.satyam.com/mediaroom/pr3nov01.html

OPC.Quality@satyam.com

http://www.satyam.com/aboutsatyam/a philosophy.html 